\title{
Implementasi Metode Fuzzy Analytic Hierarchy Process (F-AHP) Untuk Penentuan Kelas Unggulan Di SMPN 2 Tanjung Lago
}

\author{
Moh Hafiz Trisaputra \& Ari Muzakir, \\ Fakultas Ilmu Komputer, Universitas Bina Darma \\ Email: Mmhafiz64@gmail.com
}

\begin{abstract}
Education is a continuous process that contains elements of teaching, guidance, training and leadership with the specific aim of transferring various knowledge, values, and cultures. In education at a school, there must be a superior class. The superior class is a class that provides special service programs for students by developing their talents and creativity to meet the needs of students who have the potential for intelligence and talent of students. One way to determine the superior class in a school is to create a web-based application system using the F-AHP method to make it easier for the school to determine which students enter the superior class.
\end{abstract}

Keywords: F-AHP, Superior Class.

\section{Pendahuluan}

Pendidikan merupakan suatu proses terus menerus yang mengandung unsur pengajaran, bimbingan, latihan dan pimpinan dengan tujuan khas kepada pemindahan berbagai ilmu, nilai, dan budaya (Ramayulis,2002). Sekolah merupakan institusi pendidikan yang merupakan sistem pembinaan yang bersifat mengembangkan potensi para siswa, baik dari segi akademik maupun non- akademik. Suasana sekolah pada umumnya dan suasana kelas pada khususnya merupakan modal penting bagi jerninya pikiran untuk mengikuti pelajaran.

SMP Negeri 2 Tanjung Lago adalah salah satu sekolah menengah pertama negeri terbaik di, kabupaten banyuasin — Sumatera Selatan, yang terletak di Jalan Raya Tanjung ApiApi KM.43, Suka Damai, Kec. Tanjung Lago dan terakreditasi "A" , dan memiliki 18 kelas masing- masing terdiri dari 6 kelas di stiap angkatanya, pada saat kenaikan kelas, dan penerimaan siswa baru sekolah ini selalu mempunyai kelas unggulan untuk siswa yang tergolong berprestasi berdasarkan hasil ujian akhir yang mereka dapat. Berdasarkan hasil wawancara saya dengan ibu Nurjannah, selaku Kepala Staff Tata Usaha (TU) SMPN 2 Tanjung Lago pada tanggal 24 mei 2021 Adapun sistem yang berjalan di SMPN 2 Tanjung Lago serta kriteria siswa yang masuk kelas unggulan yaitu : Sistem pembelajarannya menggunakan kurikulum 2013, yang meliputi kegiatan belajar mengamati, menanya, mengumpulkan informasi, mengasosiasi atau menganalisis serta mengkomunikasikan dan selama terjadinya pandemi covid-19 ini sekolah menerapkan sistem genap ganjil. Selanjutnya kriteria siswa yang masuk kelas unggulan terdiri dari bidang akademik dan non akademik, namun yang paling diutamakan adalah prestasi akademiknya. kelas unggulan tersebut terdiri dari 2 kelas di setiap angkatannya.

Untuk bidang akademik siswa harus memiliki kriteria sebagai berikut :

Mendapat peringkat 1-5 di kelas, nilai akhir semester ganjil dan genap minimal 8,5 serta 
mendapatkan nilai 8 untuk pelajaran matematika, bahasa Indonesia dan bahasa Inggris. Dan untuk bidang non akademik siswa harus memiliki kriteria sebagai berikut : Mengikuti ekstrakurikuler di sekolah di utamakan Pramuka. mendapatkan nilai A untuk ekstrakulikuler yang di ikuti dan aktif dalam berorganisasi.

Dalam melakukan seleksi untuk menentukan jumlah siswa yang masuk kelas unggulan SMP NEGERI 2 TANJUNG LAGO terdapat masalah pada pelaksanaanya seperti input data nilai akhir siswa yang menggunakan kurikulum 2013 dengan jumlah siswa lebih kurang 180 perkelasnya yang masih menggunakan cara manual, membuat para guru dan staff mengalami kesulitan untuk menginput nilai akhir para siswa tersebut.

Sehingga pada penelitian ini penulis ingin membuat sistem/aplikasi dengan menerapkan metode fuzzy analytic hierarchy process (F- AHP) untuk penentuan kelas unggulan dengan menampilkan buton load file untuk data-data siswa yang mau di uji dan buton $F$ $A H P$ untuk melakukan pengujian hasil $F-A H P$ terhadap siswa mana saja yang masuk kelas unggulan.

Berdasarkan latar belakang tersebut, maka peneliti akan membuat penelitian dengan judul "IMPLEMENTASI METODE FUZZY ANALYTIC HIERARCHY PROCESS (F-AHP) UNTUK PENENTUAN KELAS UNGGULAN DI SMP NEGERI 2 TANJUNG LAGO”. Untuk membantu para guru dan staff dalam menentukan siswa yang masuk kelas unggulan, metode fuzzy analytic hierarchy process (F- AHP) merupakan metode yang memperhitungkan validitas data dengan adanya batas toleransi inkonsistensi berbagai kriteria yang dipilih (Tri, 2013).

\section{Tinjauan Literatur}

\subsection{Sistem pendukung keputusan}

Sistem Pendukung keputusan pertaman kali diperkenalkan pada awal tahun1970-an oleh Michel S.Scott morton dengan istilah Management Decision System,Eniyati (2010 : 136). Konsep sistem pendukung keputusan ditandai dengan sistem interaktif berbasis komputer yang membantu pengambil keputusan memanfaatkan data dan model untuk menyelesaikan masalah - masalah yang tidak terstruktur.

Sistem pendukung keputusan merupakan sistem informasi interaktif yang menyediakan informasi, pemodelan dan pemanipulasian data. Sistem ini digunakan untuk membantu pengambil keputusan dalam situasi semiterstruktur dan situasi tidak terstruktur dimana tak seorang pun tahu secara pasti bagaimana keputusan seharusnya dibuat. Ciri utama sekaligus keunggulan sistem pendukung keputusan adalah kemampuannya menyelesaikan masalah yang tidak terstruktur (Antoni, Fikari \& Akbar, 2018; Antoni \& Akbar, 2019; Antoni, Jie \& Abareshi, 2020; Antoni, Herdiansyah, Akbar \& Sumitro, 2021).

\subsection{Analytic Hierarchy Process (AHP)}

Analytic Hierarchy Process (AHP) diperkenalkan oleh DR.Thomas L. saat diawal tahun 1970, AHP merupakan prosedur yang memiliki basis matematis sangat baik dan sesuai untuk mengevaluasi berbagai atribut kualitatif. Dengan AHP juga dapat menguji konsistensi penilaian jika terjadi penyimpangan yang terlalu jauh darinilai konsistensi sempurna maka akan menunjukan penilaian perlu diperbaiki. 
Langkah-langkah metode AHP, adalah sebagai berikut ( Kusrini, 2007).

1. Mendefinisikan masalah dan menentukan solusi kedalam struktur hirarki.

2. Membuat perbandingan berpasangan.

3. Menentukan prioritas elemen.

Tahap dalam menentukan prioritas elemen adalah :

1. menyusun matriks perbandingan berpasangan, yaitu membandingkan elemen secara berpasangan sesuai kriteria yang diberikan

2. Matriks perbandingan berpasangan diisi dengan menggunakan bilangan untukmerepresentasikan kepentingan relatif dari setiap elemen.

\subsection{Fuzzy Analytical Hierarchy process (F-AHP)}

Menurut Kusrini (2007 : 3) F- AHP merupakan gabungan metode AHP dengan pendekatan konsep fuzzy. F- AHP menutupi kelemahan yang terdapat pada AHP, yaitu permasalahan terhadap kriteria yang memiliki sifat subjektif lebihbanyak. Penentuan derajat keanggotaan Fuzzy AHP yang dikembangkan menggunakan fungsi keanggotaan segita (Triangular Fuzzy Number/TFN).

\subsection{Logika Fuzzy}

Logika Fuzzy pertama kali dikembangkan oleh Lotfi A. Zadeh seorang ilmuwan Amerika Serikat berkebangsaan Iran dari Universitas California di Berkeley. Meskipun demikian logika fuzzy lebih banyak dikembangkan oleh praktiisi jepang ( Novan Parmongan, 2011). Logika fuzzy adalah cabang dari sistem kecerdasan buatan (Aritificial Inteligent) yang mengemulasi kemampuan manusia dalam berfikir kedalam bentuk algoritma yang kemudian dijalankan oleh mesin, logika fuzzy merupakan salah satu cabang dari ilmu computer yang mempelajari tentang nilai kebenaran yang bernilai banyak. Berikut disajikan penelitian sebelumnya.

\begin{tabular}{|c|c|c|c|}
\hline No & Penelitian & $\begin{array}{ll}\text { Judul } & \& \\
\text { Metode } & \end{array}$ & Hasil Penelitian \\
\hline 1. & 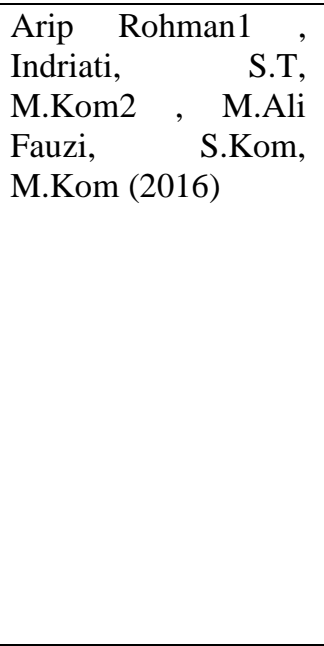 & $\begin{array}{l}\text { penentuan } \\
\text { penerimaan siswa } \\
\text { baru disma negeri } 1 \\
\text { menthobi raya } \\
\text { menggunakan } \\
\text { metodefuzzy } \\
\text { analytical hierarchy } \\
\text { process (f-ahp }\end{array}$ & $\begin{array}{l}\text { Dalam pembuatan sistem penentuan } \\
\text { penerimaan siswa baru di SMA Negeri } 1 \\
\text { Menthobi Raya menggunakan metode } \\
\text { Fuzzy Analytical Hierarchy Process (F- } \\
\text { AHP) penulis mengimplementasikan } \\
\text { langkahkerja metode F_AHP kedalam } \\
\text { sistem meliputi: Membuat matriks } \\
\text { perbandingan berpasangan,Transformasi } \\
\text { triangular fuzzy number (TFN) terhadap } \\
\text { skala AHP, Menentukan nilai sintesis } \\
\text { fuzzy, Menentukan nilai vector } \\
\text { (V) dan nilai ordinat defuzzyfikasi('d), } \\
\text { Normalisasibobot vektor (W), } \\
\text { Menghitungrasio konsistensi dan } \\
\text { Menghitung bobot alternatif akhir tiap } \\
\text { kriteria. S }\end{array}$ \\
\hline
\end{tabular}




\begin{tabular}{|c|c|c|c|}
\hline 2. & $\begin{array}{l}\text { Muhammad Fajri1, } \\
\text { Rekyan Regasari } \\
\text { MardhiPutri2 , } \\
\text { Lailil } \\
\text { Muflikhah (2018). }\end{array}$ & $\begin{array}{l}\text { Implementasi } \\
\text { Metode Fuzzy } \\
\text { Analytic Hierarchy } \\
\text { Process(F- } \\
\text { AHP)Dalam } \\
\text { Penentuan } \\
\text { Peminatan di } \\
\text { MAN 2 KotaSerang. } \\
\text { Metode FuzzyAHP. }\end{array}$ & $\begin{array}{l}\text { Dalam hasil penelitian akan dijelaskan } \\
\text { mengenai proses pengujian sistem. } \\
\text { sistem diuji menggunakan pengujian } \\
\text { fungsional dan pengujian akurasi. Pada } \\
\text { pengujian fungsional digunakan untuk } \\
\text { mengukur apakah metode fuzzy-AHP } \\
\text { yangditerapkan pada sistem berjalan } \\
\text { dengan baik. Dan pengujian akurasi } \\
\text { digunakan untukmengukur tingkat } \\
\text { akurasi dari hasil yang dihasilkan oleh } \\
\text { sistem dengan membandingkan data } \\
\text { pakar dengan data keluaran dari } \\
\text { sistem.data yang digunakan. }\end{array}$ \\
\hline 3. & $\begin{array}{l}\text { Agung } \quad \text { Nugroho } \\
(2020)\end{array}$ & $\begin{array}{l}\text { Implementasimetode } \\
\text { ana } \\
\text { lytical hierarchy } \\
\text { process } \\
\text { (ahp) terhadap } \\
\text { penerimaanbeasiswa } \\
\text { berprestasi di mts } \\
\text { walisongosidowangi. } \\
\text { Metode AHP. }\end{array}$ & $\begin{array}{l}\text { Dari hasil penerapan dan pengujianmeto } \\
\text { de AHP terhadap kriteria- kriteria yang } \\
\text { digunakan dalam melakukan seleksi } \\
\text { siswaberprestasi pada MTs Walisongo } \\
\text { Sidowangi sengan hasiljumlah total } \\
\text { bobot semua kriteria }=1(100 \%) \text { sesuai } \\
\text { dengan kaidah pembobotan dimana } \\
\text { jumlahtotal bobot harus } \\
\text { bernilai } 100 \text {. Tabel Pembobotan } \\
\text { menunjukkan bahwa dengan } \\
\text { penggunaan metodeAHP, maka }\end{array}$ \\
\hline 4. & $\begin{array}{lc}\text { Pradana } & \text { Abdi } \\
\text { Dzil } & \text { Ikram, } \\
\text { Rekyan } & \text { Regasari M } \\
\text { P, M. Ali } \\
\text { Fauzi (2016) }\end{array}$ & $\begin{array}{l}\text { implementasi metode } \\
\text { f-ahpuntuk } \\
\text { menentukan prioritas } \\
\text { pemberian bantuan } \\
\text { saranadan prasarana } \\
\text { sekolah dasar(studi } \\
\text { kasus: unitpelaksana } \\
\text { teknis dinas } \\
\text { kecamatan gresik). } \\
\text { MetodeF-AHP. }\end{array}$ & $\begin{array}{l}\text { Hasil perhitungan yangdidapatkan dari } \\
\text { penelitin yang dilakukan penulis } \\
\text { dilakukanpengunjian korelasi dengan } \\
\text { hasilprioritas yang didapatkan dari } \\
\text { UPTD Kecamatan Gresik. }\end{array}$ \\
\hline 5. & $\begin{array}{l}\text { Muhammad Eka } \\
\text { Putra Galus, Nerfita } \\
\text { NikentariST., M.Cs, } \\
\text { Sulfikar } \quad \text { Sallu } \\
\text { S.Kom., M.Kom } \\
(2015) \text {. }\end{array}$ & $\begin{array}{l}\text { Analis } \\
\text { penggunaan } \\
\text { metode ahpdan } \\
\text { fuzzy ahppada } \\
\text { perankingan siswa } \\
\text { (studikasus : smk } \\
\text { negeri } 1 \text { batam). } \\
\text { Metode F-AHP. } \\
\end{array}$ & $\begin{array}{l}\text { Perbedaan hasil yang didapat } \\
\text { dikarenakan penggunaan metode AHP } \\
\text { dan Fuzzy AHP kriteriapenilaiannya } \\
\text { memiliki bobot penilaian yang berbeda- } \\
\text { beda,sedangkan pada rumus dari SMK N } \\
1 \text { Batam bobot penilaian kriteriabernilai } \\
\text { sama. }\end{array}$ \\
\hline
\end{tabular}

\section{Metode Penelitian}

\subsection{Analisis}

Tipe penelitian yang digunakan oleh penulis merupakan tipe penelitian implementatif. Pada bab ini menjelaskan metode mengenai langkah-langkah yang digunakan dalam implementasi metode fuzzy analytic hierarchy process (F-AHP) dalam penentuan kelas unggulan di SMPN 2 Tanjung Lago.

Secara umum langkah-langkah penelitian yang dilakukan ditunjukan pada gambar 3.1 di bawah ini 


\section{IPSII

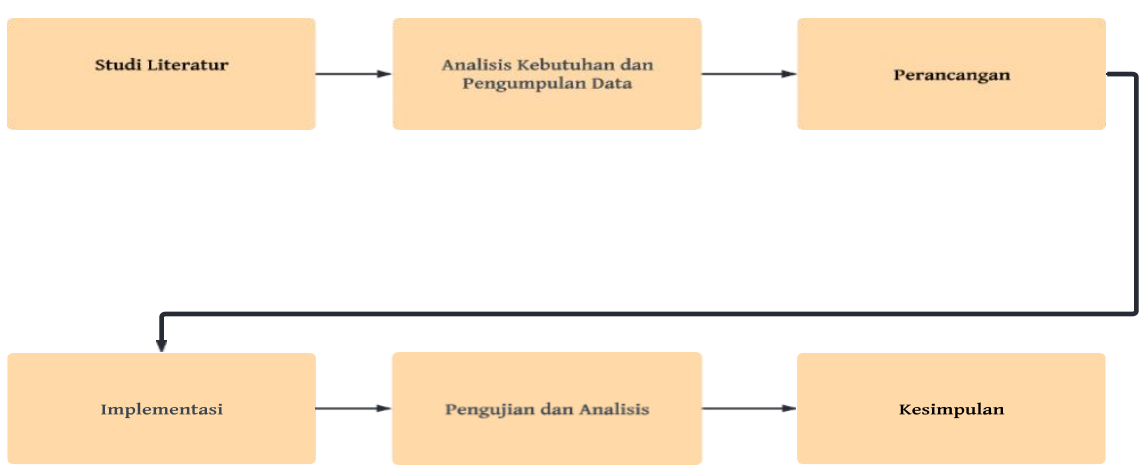

Gambar 3.1 Langkah Penelitian.

\subsection{Perancangan Sistem}

Pada tahap ini terdiri dari perancangan sistem dan desain antar muka yang dibuat berdasarkan kebutuhan masukan dan keluaran,berikut ini gambaran umum dari sistem penentuan kelas unggulan dengan menggunakan metode F-AHP serta rancangan interfance dari aplikasi yang akan dibuat.

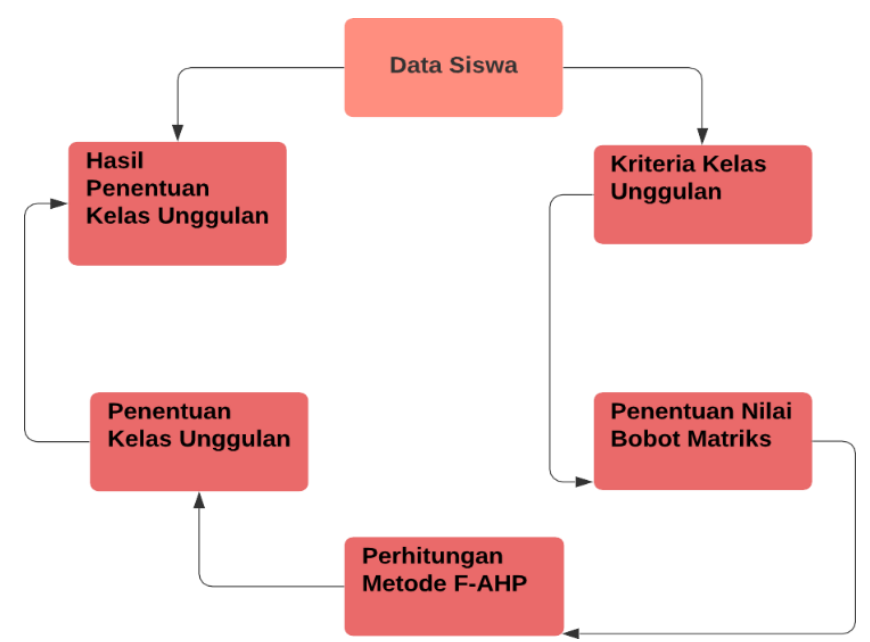

Gambar 3.2 Perancangan Sistem

\section{Hasil dan Pembahasan}

Dari hasil penelitian yang telah dilakukan di SMPN 2 Tanjung Lago. Rancangan aplikasi kelas unggulan dibangun untuk memudahkan para staff SMPN 2 Tanjung Lago untuk menentukan siswa mana saja yang masuk kelas unggulan. Aplikasi ini terdiri dari beberapa menu. Adapun menu-menu tersebut yaitu :

1. Halaman menu utama, pada menu utama terdapat menu load file yang berfugsi untuk load file excel data-data siswa yang akan diuji.

2. Menu Open merupakan menu pada user yang digunakan untuk memilih dan memasukan file.

3. Menu Button F-AHP untuk melakukan pengujian hasil fuzzy terhadap siswa mana saja yang masuk kelas unggulan. 
Aplikasi penentuan kelas unggulan di SMPN 2 Tanjung Lago, menggunakan sequence flow map untuk menentukan langkah penelitian, Activity Diagram menunjukan aktivitas tahapan analisis sistem dalam merancang aplikasi, Use case untuk menganalisis setiap fase dari analisis system, Cluster Chart menunjukan tahapan perancangan sistem dan desain antar muka serta menggunakan UML dalam membuat activity sistem yang berjalan.

Pada aplikasi ini menggunkakan pengujian sistem perangkat lunak yang menggunakan black box testing yang digunakan untuk menguji perangkat lunak tanpa mengetahui struktur internal kode atau program. Metode ini digunakan untuk memeriksa apakah Aplikasi penentuan kelas unggulan di SMPN2 Tanjung Lago memberikan hasil yang dapat memudahkan para staff dalam menentukan dan mengelolah data siswa mana saja yang masuk kelas unggulan.

\section{Kesimpulan}

Berdasarkan dari hasil penelitian dan pembahasan yang di lakukan oleh penulis dapat ditarik kesimpulan bahwa :

1. Ada tiga teori terkait dalam penelitian ini yatitu, Kelas Unggulan, Analytical Hierarchy Process (AHP) dan Fuzzy Analytical Hierarchy Process (F-AHP) serta terdiri dari beberapa tahapan perancangan, diantaranya iyalah perhitungan metode F-AHP, prioritas perngkingan dan perancangan antar muka.

2. Pengolahan data dan perhitungan maualisasi diambil dari nama-nama siswa SMPN 2 Tanjung Lago tahun ajaran 2019/2020 yang berjumlah 184 siswa.

3. Hasil pengujian fungsional sistem penentuan kelas unggulan di SMPN 2 Tanjung lago memiliki tingkat persentase sebesear 100\%.

\section{Referensi}

Antoni, D., Herdiansyah, M. I., Akbar, M., \& Sumitro, A. (2021). Pengembangan Infrastruktur Jaringan Untuk Meningkatkan Pelayanan Publik di Kota Palembang. JURNAL MEDIA INFORMATIKA BUDIDARMA, 5(4), 1652-1659.

Antoni, D., Jie, F., \& Abareshi, A. (2020). Critical factors in information technology capability for enhancing firm's environmental performance: case of Indonesian ICT sector. International Journal of Agile Systems and Management, 13(2), 159-181.

Antoni, D., \& Akbar, M. (2019). E-supply chain management value concept for the palm oil industry. Jurnal Sistem Informasi, 15(2), 15-29.

Antoni, D., Fikari, D., \& Akbar, M. (2018). The readiness of palm oil industry in enterprise resource planning. Telkomnika, 16(6), 2692-2702.

Fauzi, F., Dencik, A. B., \& Asiati, D. I. (2019). Metodologi Penelitian untuk manajemen dan akuntansi. Jakarta: Salemba Empat.

Nugroho A. IMPLEMENTASI METODE ANALYTICAL HIERARCHY PROCESS ( AHP ) TERHADAP PENERIMAAN BEASISWA BERPRESTASI DI MTS WALISONGO Abstraksi. 2020;3(2):1-5.

Ependi U, Kunang Y, Novifika S. Implementasi Metode Rational Unified Process Pada Mobile Digital Library. J Ilm Matrik. 2014;(03):35-44. 
D’Arcy Wentworth Thompson. No Title No Title. Angew Chemie Int Ed 6(11), 951-952. Published online 1967.

Rohman A, Kom M, Fauzi MA, Kom S, Kom M. Penentuan Penerimaan Siswa Baru Di Sma Negeri 1 Menthobi Raya Menggunakan Metode Fuzzy Analytical Hierarchy Process ( F-Ahp ) Penentuan Penerimaan Siswa Baru Di Sma Negeri 1 Menthobi Raya. 2018;(April):1-9.

Bantuan P, Dan S, Sekolah P. Abstrak. :1-8.

Fajri M, Putri RRM, Muflikhah L. Implementasi Metode Fuzzy Analytic Hierarchy Process (F-AHP) Dalam Penentuan Peminatan Di MAN 2 Kota Serang. Vol 2.; 2018.

Kristianto. Landasan Teori. LandasanteoriCom. 2018;(2003):1-12. http://www.landasanteori.com/2015/09/pengertian-kreativitas-definisi-aspek.html

Fajri M, Putri RRM, Muflikhah L. Implementasi Metode Fuzzy Analytic Hierarchy Process (F-AHP) dalam Penentuan Peminatan di MAN 2 Kota Serang. J Pengemb Teknol Inf dan Ilmu Komput. 2018;2(5):2109-2117.

\section{Copyrights}

Copyright for this article is retained by the author(s), with first publication rights granted to the journal.

This is an open-access article distributed under the terms and conditions of the Creative Commons Attribution license (http://creativecommons.org/licenses/by/4.0/) 